\title{
Erratum to: Synchronous degassing patterns of the neighbouring volcanoes Llaima and Villarrica in south-central Chile: the influence of tidal forces
}

\author{
Stefan Bredemeyer · Thor H. Hansteen
}

Published online: 6 June 2014

(C) Springer-Verlag Berlin Heidelberg 2014

\section{Erratum to: Int J Earth Sci (Geol Rundsch) DOI 10.1007/s00531-014-1029-2}

The original article has been published with a misleading error on page 11 (bottom left), second sentence of subsection The fortnightly cycle. The respective sentence reads:

As the diurnal and semidiurnal rates of stress changes are larger than the fortnightly variations, except for the period around the fortnightly tidal minimum (Fig. 7b), their effect on degassing should accordingly be more pronounced, which is consistent with the high variability of the $\mathrm{SO}_{2}$ fluxes throughout a day.

The fortnightly tidal curve (black line) in Fig. $7 \mathrm{~b}$ is, however, amplified by a factor $\sim 10$ with respect to the given scale for graphical reasons. The diurnal and semidiurnal rates of stress changes are of course always (without any exception) larger than the fortnightly variations as can be seen in Fig. 3 where all the curves are depicted including a scale.

The corrected sentence should thus read as follows:

As the diurnal and semidiurnal rates of stress changes are larger than the fortnightly variations, their effect on degassing should accordingly be more pronounced, which is consistent with the high variability of the $\mathrm{SO}_{2}$ fluxes throughout a day.

The online version of the original article can be found under doi:10.1007/s00531-014-1029-2.

S. Bredemeyer $(\square)$

SFB 574, GEOMAR Helmholtz Centre for Ocean Research Kiel,

Wischhofstr. 1-3, 24148 Kiel, Germany

e-mail: sbredemeyer@geomar.de

S. Bredemeyer · T. H. Hansteen

GEOMAR Helmholtz Centre for Ocean Research Kiel,

Wischhofstr. 1-3, 24148 Kiel, Germany 